\title{
Marcello Martinelli
}

\section{Environmental cartography: methodological and practical references}

\author{
Martinelli, M.: Environmental cartography: methodological and practical references. - Bocc. \\ 28: 407. 2019. — ISSN: 1120-4060 printed, 2280-3882 online. \\ Key words: nature, society, methodology.
}

The aim of this contribution is to make a reflection upon the methodological question of environmental mapping, aiming to reach a systematization proposal. It is assumed that the considerations made regarding the environment are not only directed to nature itself, but also to society. This elaboration begins through the study of the area of interest focusing on its thematic ramifications via analysis maps. After that, a synthesis approach is made which would confirm analysis characterized by groups of features or variables - the Types of environment - also present in relevant literature on types of landscapes, which would be traced over the synthesis map.

Address of the author:

Marcello Martinelli,

Pós-graduação. Programa Geografia Humana, Departamento de Geografia, Faculdade de Fisosofia, Letras e Ciências Humanas, Universidade de São Paulo, Brasil. E-mail: marcello.martinelli.3@gmail.com 
